\begin{tabular}{c} 
JOURNAL OF APPLIED SMART ELECTRICAL \\
NETWORK AND SYSTEMS (JASENS) \\
\hline ISAS
\end{tabular}

\title{
Sistem Kendali Pengisian Jus Otomatis Menggunakan Sensor Infrared Dan Waterflow Berbasis PLC
}

\author{
Siti Afiyah Qatrunnada ${ }^{1}$, Yurni Oktarina ${ }^{2}$, Tresna Dewi ${ }^{3 *}$, Evelina ${ }^{4}$, Pola Risma ${ }^{5}$ \\ 1,2,3,4,5 Jurusan Teknik Elektro, Politeknik Negeri Sriwijaya \\ 1afiyahnadaa@gmail.com, 2yurni_oktarina@polsri.ac.id,3tresna_dewi@polsri.ac.id*, \\ ${ }^{4}$ evelinaginting@gmail.com, ${ }^{5}$ polarisma@polsri.ac.id
}

\begin{abstract}
The need for automatic beverage vendors is quite high in public places and crowds, which will be more efficient and efficient than the beverage vendors who are human-friendly. This paper discusses the design of an automatic beverage vendor based on a programmable logic controller (PLC). The PLC used for this study is the production of Outseal, which has an Outseal Studio simulation program with a ladder diagram control. This automatic beverage vendor consists of input, process, and output. The primary input of this system is an infrared sensor, and a flow meter sensor to detect the cup's presence and how much juice poured to the cup. The DC motor and pump are the control output. A simulation program demonstrates the effectiveness of this automatic beverage supplier with the Outseal studio.
\end{abstract}

Keywords: automatic drinks, infrared sensors, flowmater sensors, PLC, ladder diagram

\begin{abstract}
Abstrak
Kebutuhan akan vendor minum otomatis cukup tinggi pada tempat-tempat umum dan keramaian, dimana akan lebih efisien dan hemat dibandingkan vendor minum yang dijaga oleh seorang manusia. Makalah ini membahas tentang desain vendor minum otomatis yang berbasis Programmable Logic Controller (PLC). PLC yang digunakan pada penelitian ini adalah produksi dari Outseal yang memiliki program simulasi Outseal Studio dengan kendali ladder diagram. Vendor minum otomatis ini terdiri dari input, process, dan output. Input utama sistem ini adalah sensor infrared and sensor flowmeter untuk mendeteksi keberadaan cangkir dan seberapa banyak cairan jus yang telah masuk ke dalam cangkir tersebut. Output kendali adalah motor DC dan pompa. Keefektifan vendor minum otomatis ini diperlihatkan dengan program simulasi dengan Outseal studio.
\end{abstract}

Kata kunci: minuman otomatis, sensor infrared, sensor flowmeter, PLC, ladder diagram

Diterima Redaksi : 02-06-2020 | Selesai Revisi : 10-06-2020 | Diterbitkan Online : 30-06-2020

\section{Pendahuluan}

Dalam dunia industri, proses produksi secara otomatis telah banyak digunakan oleh industri yang menghasilkan produk minuman, makanan, dan lain-lain. Salah satu contohnya adalah pengolahan dan penyajian minuman otomatis yang dapat mempermudah dan mempercepat proses pekerjaan [1][2]. Dengan menggunakan mesin pengisian otomatis dimana alat tersebut bekerja hanya dengan meletakkan gelas di atas konveyor maka disini dibuatlah mesin pengisian minuman otomatis.

Saat ini teknologi berkembang sangat cepat salah satunya teknologi pemrograman dengan menggunakan sistem kontrol logika yang dikenal dengan Programmable Logic Controller (PLC). PLC merupakan salah satu perangkat yang meningkatkan keandalan otomatisasi produksi sistem melalui input seperti sensor untuk mendeteksi benda secara real time. PLC adalah perangkat sistem otomatis yang paling banyak digunakan saat ini dalam proses produksi di industri. Teknologi pemrograman ini dapat dikendalikan secara otomatis dan dapat diselesaikan dalam waktu yang singkat, serta memiliki memori yang dapat diprogram dan menyimpan perintah-perintah untuk melakukan fungsi-fungsi khusus. Dengan proses secara otomatis, perangkat elektronik dapat mengatasi masalah tersebut dengan mempersingkat waktu, mengurangi kerugian, dan meningkatkan kualitas hasil produksi [39].

Paper ini membahas desain mesin pengisi jus otomatis ini berbasis PLC dengan menggunakan sensor infrared dan waterflow sebagai input bagi mesin otomatis ini. Mesin ini bekerja otomatis dengan memberikan input melalui tombol pilihan jus yang diinginkan. Dalam pengisian jus alat ini menggunakan pompa agar pengisian jus berjalan dengan cepat. 


\section{Metode Penelitian}

Pada alat pengisi jus buah otomatis menggunakan beberapa bahan, yaitu:

\subsection{PLC (Programmable Logic Controller)}

PLC (Programmable Logic Controller) suatu peralatan kontrol yang dapat diprogram untuk mengontrol proses atau operasi mesin. Kontrol program dari PLC adalah menganalisa sinyal input kemudian mengatur keadaan output sesuai dengan keinginan pemakai. Keadaan input PLC digunakan dan disimpan di dalam memori dimana PLC melakukan instruksi logika yang di program pada keadaan inputnya. Peralatan input dapat berupa sensor photo elektrik, push button pada panel kontrol, limit switch atau peralatan lainnya dimana dapat menghasilkan suatu sinyal yang dapat masuk ke dalam PLC. Peralatan output dapat berupa switch yang menyalakan lampu indikator, relay yang menggerakkan motor atau peralatan lain yang dapat digerakkan oleh sinyal output dari PLC. Selain itu PLC juga menggunakan memori yang dapat diprogram untuk menyimpan instruksi-instruksi yang melaksanakan fungsi-fungsi khusus seperti : logika pewaktuan, sekuensial dan aritmetika yang dapat mengendalikan suatu mesin atau proses melalui modul-modul I/O baik analog maupun digital.

\subsection{Infrared (IR)}

Infrared (IR) detektor atau sensor infra merah adalah komponen elektronika yang dapat mengidentifikasi cahaya infra merah (infrared, IR). Sensor infra merah atau detektor infra merah saat ini ada yang dibuat khusus dalam satu module dan dinamakan sebagai IR Detector Photo modules. IR Detector Photomodules merupakan sebuah chip detektor inframerah digital yang di dalamnya terdapat photodiode dan penguat (amplifier). IR Detector photo modules yang digunakan dalam perancangan robot ini adalah jenis TSOP (TEMIC Semiconductors Optoelectronics photo modules). TSOP ini mempunyai berbagai macam tipe sesuai dengan frekuensi carrier-nya, yaitu antara $30 \mathrm{kHz}$ sampai dengan $56 \mathrm{kHz}$. Tipe-tipe TSOP beserta frekuensi carrier-nya dapat dilihat pada lampiran data sheet [8].

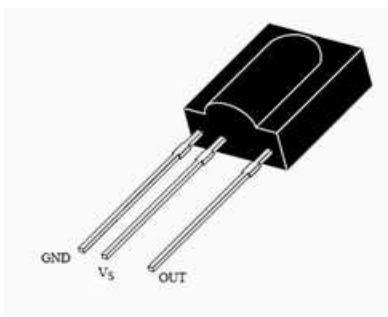

Gambar 1. Sensor Infrared (IR)

\subsection{Flowmeter}

Flowmeter adalah alat untuk mengukur jumlah atau laju aliran air dari suatu fluida yang mengalir dalam pipa atau sambungan terbuka. Alat ini terdiri dari primary device, yang disebut sebagai alat utama dan secondary device (alat bantu sekunder). Flowmeter umumnya terdiri dari dua bagian, yaitu alat utama dan alat bantu sekunder. Alat utama menghasilkan suatu signal yang merespon terhadap aliran karena laju aliran tersebut telah terganggu. Alat utamanya merupakan sebuah orifis yang mengganggu laju aliran, yaitu menyebabkan terjadinya penurunan tekanan. Alat bantu sekunder menerima sinyal dari alat utama lalu menampilkan, merekam, dan/atau mentransmisikannya sebagai hasil dari laju aliran [9].

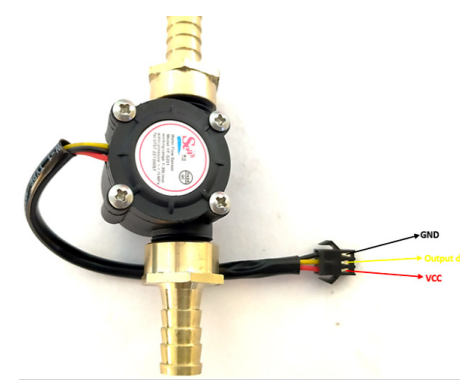

Gambar 2. Sensor Flowmeter

\subsection{Pompa Air}

Pompa Air adalah suatu rangkaian elektronika yang dikemas menjadi suatu instrumen, yang mempunyai fungsi sebagai penyedia aliran air dalam debit besar dengan prinsip kerja menghisap air yang tersedia dan mendistribusikan aliran air tersebut kepada setiap saluran keluaran air. Untuk pembagian jenis dari rangkaian pompa air dapat diklasifikasikan melalui kekuatan daya hisap, daya listrik yang dikonsumsi, level ketinggian distribusi air, dan level ketinggian penampungan air. Perhitungan dari daya hisap air dan daya listrik yang dikonsumsi biasanya akan sebanding, jadi apabila pompa air mengalirkan air dalam jumlah debit yang besar maka akan semakin besar pula daya yang dikonsumsi oleh rangkaian pompa air.

\subsection{Motor DC}

Motor DC adalah motor listrik yang memerlukan suplai tegangan arus searah pada kumparan medan untuk diubah menjadi energi gerak mekanik. Kumparan medan pada motor DC disebut stator (bagian yang tidak berputar) dan kumparan jangkar disebut rotor (bagian yang berputar). Motor arus searah, sebagaimana namanya, menggunakan arus langsung yang tidak langsung atau direct-unidirectional.

\subsection{Belt Conveyor}

Pada dasarnya belt conveyor memiliki bentuk yang sederhana. Seperti namanya conveyor belt dilengkapi dengan adanya sabuk yang dapat menahan benda-benda padat saat diangkut. Belt atau sabuk terbuat dari dari berbagai macam jenis tergantung dari sifat benda yang akan diangkut. Misalnya untuk mengangkut bahanbahan yang panas, maka diperlukan belt yang terbuat dari logam sehingga dapat tahan terhadap panas. 


\subsection{Push Button Switch}

Push button switch (saklar tombol tekan) adalah perangkat / saklar sederhana yang berfungsi untuk menghubungkan atau memutuskan aliran arus listrik dengan sistem kerja tekan unlock (tidak mengunci). Sistem kerja unlock disini berarti saklar akan bekerja sebagai device penghubung atau pemutus aliran arus listrik saat tombol ditekan, dan saat tombol tidak ditekan (dilepas), maka saklar akan kembali pada kondisi normal.

Agar keseluruhan sistem dan alat terealisasi sesuai dengan rencana dan target dibutlah beberapa kegiatan penyelesaian, yaitu:

\subsection{Blok Diagram}

Blok diagram merupakan salah satu bagian penting dalam perancangan suatu desain. Cara kerja keseluruhan rancangan desain alat pengisi jus otomatis yang akan dibuat dapat dilihat pada blok diagram sehingga keseluruhan blok diagram akan menghasilkan suatu sistem yang dapat difungsikan atau dapat bekerja secara runtut.

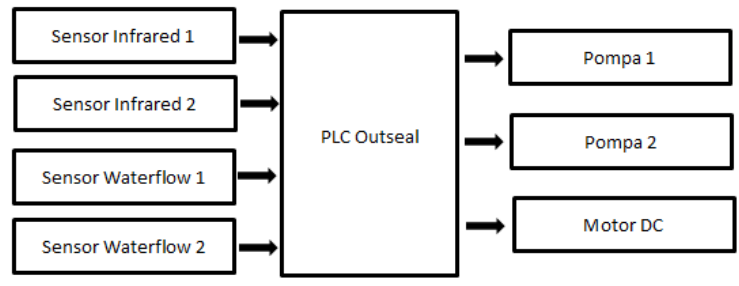

Gambar 3 Blok Diagram Alat Pengisi Jus Otomatis

Penjelasan pada setiap gambar blok diagram (Gambar.3), yaitu:

- $\quad$ Sensor Infrared

Terdapat 2 buah sensor infrared pada rancang bangun alat ini. Sensor infrared berfungsi untuk mendeteksi keberadaan gelas. Disini terdapat 2 buah sensor infrared pada setiap jus.

- Sensor Waterflow

Sensor ini berfungsi untuk mengukur jumlah laju atau aliran jus yang akan di tuang ke dalam gelas. Pada rancang bangun alat ini terdapat 2 buah sensor waterflow, dimana sensor 1 terdapat pada jus jambu dan sensor 2 terdapat pada jus apel.

- PLC Outseal

PLC berfungsi sebagai pengontrol dan sebagai media penyimpan program dimana semua program yang digunakan mengaktifkan semua perangkat yang tersimpan didalamnya.

- Pompa Pompa berfungsi untuk penyedia aliran air untuk memprogram outseal PLC secara visual dalam debit besar dengan prinsip kerja menggunakan ladder diagram. menghisap air dan mendistribusikan air ke saluran keluar air. Di sini terdapat 2 buah pompa pada setiap jus.

- $\quad$ Motor DC $12 \mathrm{~V}$
Motor DC 12V berfungsi sebagai pengerak dari konveyor.

\subsection{Perancangan Algoritma (Software)}

Proses algoritma alat pengisi jus otomatis adalah sebagai berikut :

- Start.

- Menekan push button merah atau hijau.

- Konveyor menyala.

- Sensor infrared mendeteksi keberadaan gelas.

- $\quad$ Pompa menyala dan sensor waterflow memberi jumlah aliran yang akan dikeluarkan.

- Konveyor berhenti.

- Pompa mengeluarkan jus ke dalam gelas.

- Konveyor jalan kembali.

- Jika telah mencapai kondisi akhir konveyor akan berhenti.

Flow chart alat pengisi jus otomatis dapat dilihat pada (Gambar 4)

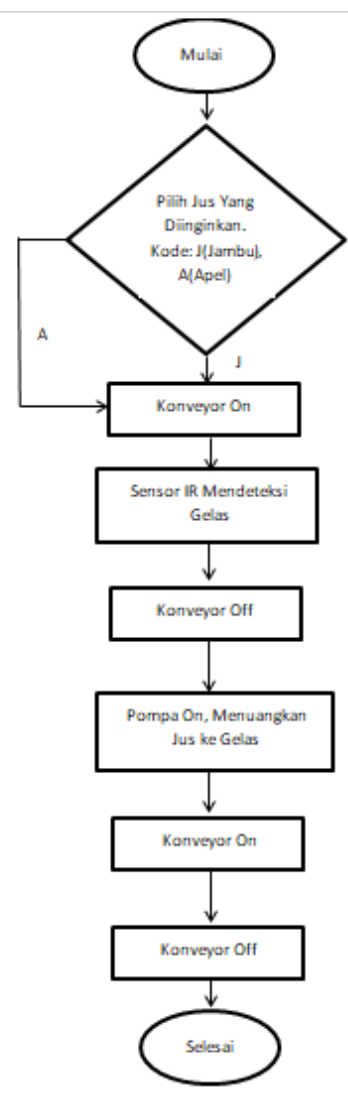

Gambar 4 Flowchart Alat Pengisi Jus Otomatis

\section{Hasil dan Pembahasan}

Dalam penelitian ini, jenis software yang digunakan adalah Outseal Studio. Outseal studio adalah sebuah program komputer karya anak bangsa. yang digunakan

Pada Gambar 5 merupakan kondisi ketika memilih jus jambu. Terlihat bahwa S.1 memberikan masukan 1 (terbuhung) pada PLC yang kemudian menyebabkan B.1 yang menandakan konveyor berjalan. S.2 sebagai sensor 
infrared menyala menandakan bahwa terdapat gelas Pada Gambar 7 adalah kondisi ketika memilih jus apel. yang terdeteksi dimana menyebabkan T.1.DN akan Terlihat bahwa S.4 memberikan nilai masukkan 1 berkerja dengan interval sebesar 1 detik dan preset (terhubung) pada PLC yang menyebabkan B.1 yang sebesar 30 untuk memberhentikan konveyor. Kemudian menandakan konveyor akan berjalan. Kemudian S.5 B.2 yang menandakan pompa untuk jus jambu akan sebagai sensor infrared menyala yang menadakan menyala.

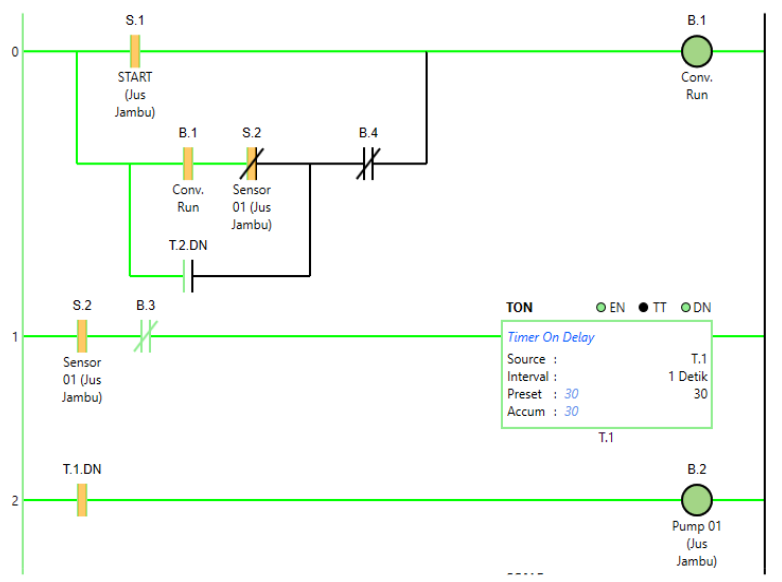

Gambar 5 Saat Memilih Jus Jambu

Pada Gambar 6 terdapat SCALE dengan nilai scale max 500 dan terdapat GRT dengan sumber B sebesar 250 untuk memberi nilai debit jus yang akan dikeluarkan oleh pompa jus untuk mengisi gelas. Kemudian terdapat T.2.DN dengan interval sebesar 1 detik dan preset sebesar 10 untuk kembali menyalakan konveyor.

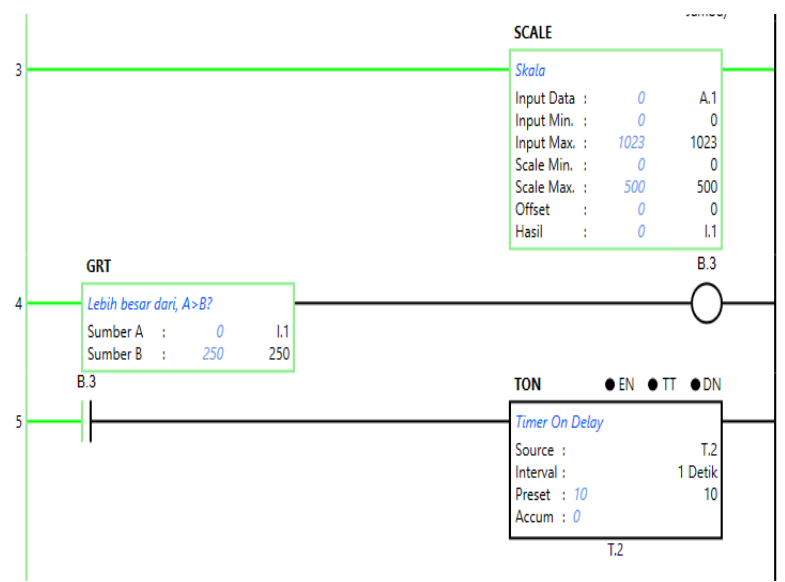

Gambar 6 Pengisian Jus Jambu Ke Dalam Gelas bahwa terdapat gelas yang terdeteksi dan menyebabkan T.3.DN akan berkerja dengan interval sebesar 1 detik dan preset sebesar 30 untuk memberhentikan konveyor, lalu B.2 yang menandakan pompa untuk jus apel akan menyala.

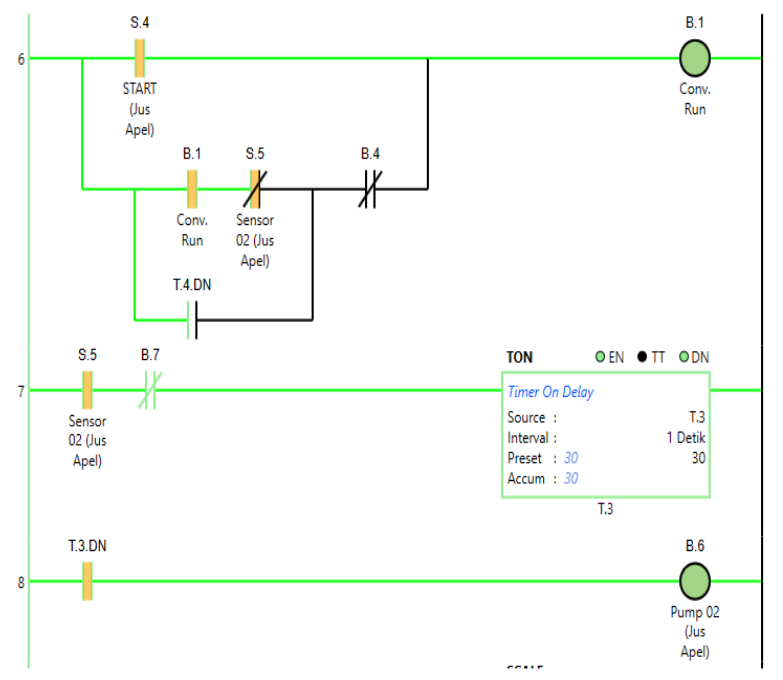

Gambar 7 Simulasi Saat Memilih Jus Apel

Pada Gambar 8 terdapat SCALE dengan nilai scale max 500 dan terdapat GRT dengan sumber B sebesar 250 untuk memberi nilai debit jus yang akan dikeluarkan oleh pompa jus apel untuk mengisi jus apel ke dalam gelas. Kemudian terdapat T.4.DN dengan interval sebesar 1 detik dan preset sebesar 10 untuk kembali menyalakan konveyor.

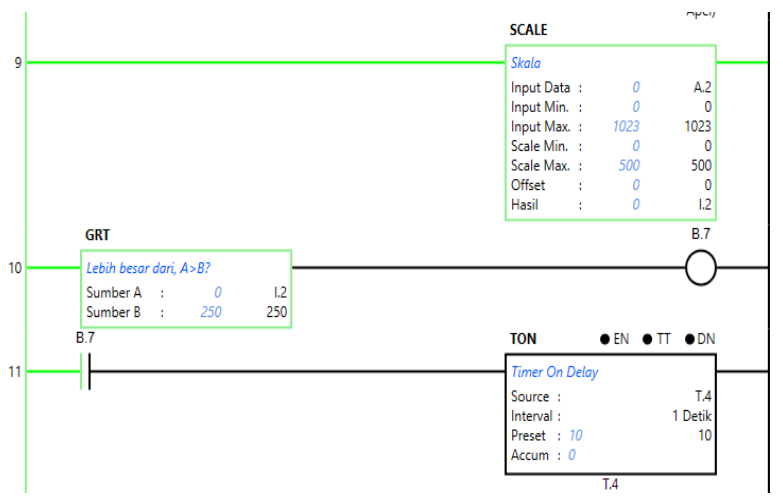

Gambar 8 Pengisian Jus Apel Ke Dalam Gelas

\section{Kesimpulan}

Dari penelitian yang telah dilakukan, alai pengisian jus otomatis ini dibuat untuk mengatasi kebutuhan manusia dalam mengkonsumsi jus buah dengan proses penyajian yang efesien. Metode yang diperoleh untuk mengindetifikasi alat pengisian jus otomatis ini menggunakan PLC dengan menentukan input dan output 
yanng digunakan, memberi alamat pada input dan output, dan membuat program ladder diagram di outseal studio. Sensor yang digunakan adalah sensor infrared dan sensor flowmeter karena lebih praktis dan akurat dibandingkan jika menggunakan sensor warna dan solenoid valve.

\section{Daftar Rujukan}

[1] Dewi T., Risma P., and Oktarina Y., 2020, Fruit Sorting Robot Based on Color and Size for an Agricultural Product Packaging System, Bulletin of Electrical Engineering, and Informatics (BEEI), 9(4), pp. 1438-1445. doi:10.11591/eei.v9i4.2353.

[2] Oktarina Y., Dewi T., Risma P., and Nawawi M., 2020, Tomato [8] Harvesting Arm Robot Manipulator; a Pilot Project, Journal of Physics: Conference Series, 1500, p. 012003. doi: 0.1088/17426596/1500/1/012003. [3] Schutz D., Wannagat A., Ligat C., and Vogel-Heuser B., 2013. [9]
Development of PLC-Based Software for Increasing the Dependability of Production Automation Systems. IEEE Transactions on Industrial Informatics, 9(4), pp. 2397-2406. doi: 10.1109/TII.2012.2229285.

[4] Gaikwad R., Kharat S. M. M., and Thakur J., 2017, PLC Based Automatic Car Washing System Using Proximity Sensors. 2017
Proc. ICPSCSI 21-22 Sept. 2017, Chennai: India. doi: 10.1109/ICPCSI.2017.8392041.

] Prasetyani L., Ramadhan B., Dewi T., and Sarfat W., 2019, PLC Omron CJ1M CPU-21 Control Modification for Drill Oil Hole Machine in an Automotive Company, Journal of Physics: Conference Series, 1500, p. 012039.

[6] Tirian G. O., Chioncel C. P., Holubeck R., and Cinkar K., 2020, PLC Programming to Optimize Water Flow in Secondary Cooling Zone, Journal of Physics: Conference Series, 1426, p. 012020. doi:10.1088/1742-6596/1426/1/012020

[7] Bayindir R., and Cetinceviz Y., 2011, A water Pumping Control System with a Programmable Logic Controller (PLC) and Industrial Wireless Modules for Industrial Plants- An Experimental Setup, ISA Transaction, 50(2), pp. 321-328. https://doi.org/10.1016/j.isatra.2010.10.006

Alphonsus E. R., and Abdullah M. O., 2016, A Review on the Applications of Programmable Logic Controller (PLCs), Renewable and Sustainable Energy Review, 60, pp. 1185-1205. https://doi.org/10.1016/i.rser.2016.01.025.

Su H., Luo Z., Feng Y., and Liu Z., 2019, Application of Siemens PLC in Thermal Simulator Control System, Procedia Manufacturing, 37, pp. 38-45.

https://doi.org/10.1016/j.promfg.2019.12.009. 